\title{
Bridges and Mediation in Higher Distance Education: HELMeTO 2020 Report
}

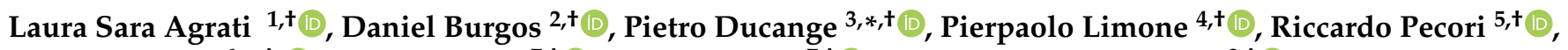

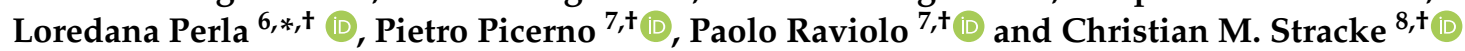

1 Department of Humanities and Social Sciences, University of Bergamo, I-24129 Bergamo, Italy; laurasara.agrati@unibg.it

2 Research Institute for Innovation \& Technology in Education, Universidad Internacional de La Rioja (UNIR), Logroño, E-26006 La Rioja, Spain; daniel.burgos@unir.net

3 Department of Information Engineering, University of Pisa, I-56122 Pisa, Italy

4 Department of Humanities, Cultural Heritage, Education Sciences, University of Foggia, I-71122 Foggia, Italy; pierpaolo.limone@unifg.it

5 Department of Engineering, University of Sannio, I-82100 Benevento, Italy; riccardo.pecori@gmail.com

6 Department of Educational Sciences, Psychology, Communication,University of Bari “Aldo Moro", I-70122 Bari, Italy

7 Faculty of Psychology, eCampus University, I-22060 Novedrate, Italy; pietro.picerno@uniecampus.it (P.P.); paolo.raviolo@uniecampus.it (P.R.)

8 European Institute for Learning, Innovation and Cooperation, D-53225 Bonn, Germany; stracke@elc-institute.org

* Correspondence: pietro.ducange@unipi.it (P.D.); loredana.perla@uniba.it (L.P.)

+ These authors contributed equally to this work.

Citation: Agrati, L.S.; Burgos, D.; Ducange, P.; Limone, P.; Pecori, R.; Perla, L.; Picerno, P.; Raviolo, P.; Stracke, C.M. Bridges and Mediation in Higher Distance Education: HELMeTO 2020 Report. Educ. Sci. 2021, 11, 334. https://doi.org/ 10.3390/educsci11070334

Academic Editor: Han Reichgelt

Received: 2 June 2021

Accepted: 1 July 2021

Published: 5 July 2021

Publisher's Note: MDPI stays neutral with regard to jurisdictional claims in published maps and institutional affiliations.

\section{Copyright: (c) 2021 by the authors.} Licensee MDPI, Basel, Switzerland. This article is an open access article distributed under the terms and conditions of the Creative Commons Attribution (CC BY) license (https:// creativecommons.org/licenses/by/ $4.0 /)$.

\begin{abstract}
In this paper, we report the scientific experience of HELMeTO 2020, the second edition of the International Workshop on Higher Education Learning Methodologies and Technologies Online, held virtually in Bari (Italy) in September 2020 because of the COVID-19 pandemic. The call received 59 proposals from nine countries, 39 papers were accepted to the virtual workshop and 26 full papers were finally selected to be published in the proceedings. The workshop illustrated a fast-developing scenario in which the epidemic emergency accelerated the dissemination and consolidation of online learning in higher education. A specific focus of the workshop can be identified as students' learning experience, with studies on tutoring and active learning approaches, personalized solutions supported by data analysis, virtual reality and an in-depth analysis of human-computer interactions.
\end{abstract}

Keywords: distance learning; higher education; technology-enhanced learning; digital learning; online education; e-Learning; COVID-19

\section{Introduction}

In the last two decades, the number of online university courses available worldwide has risen consistently, as well as the number of students and academic staff involved in this new way of implementing higher education. This spread was driven both by social (increasing number of working or disabled students) and technological (virtual learning environments, broadband communications, etc.) changes.

Online collaboration, communities and courses were enabled thanks to Web 2.0 and social media, including the first massive open online course (MOOC) in 2008 [1,2]. In the 2010s, e-Learning became mature, in particular in enterprises and their vocational training. However, the focus was often on the technology and on the simple transfer of face-toface learning and paper-based materials into digital environments. Thus, innovative methodologies and specific pedagogical approaches in online learning were demanded under the umbrella term of "Open Education" that was influencing policies, methodologies and practices [2,3]. As a consequence, open online learning approaches entered official curricula in schools and higher education institutions [3]. 
However, this growing interest for online higher education required standardization and distance quality assessment procedures, which led online higher education to become a critical aspect in many academic organizations, especially if one considers the framework of the Bologna Process and its progressive deployment that led to the European Higher Education Area initiative.

The COVID-19 pandemic began in 2020 and is still affecting the whole world in a way that neither globalization nor the establishment of the worldwide Internet were able to achieve over several decades. The pandemic impacted all sectors, branches and levels of society, including formal higher education and the involved academic institutions [4-7]. COVID-19's impact was unique in many aspects and led to many ad hoc decisions and changes: most educators and learning providers were not prepared and forced to move to distance education without specific comprehension of the online education phenomenon. eLearning was considered as a potential solution, but many of the involved parties (students, instructors, learning providers, educational systems and ministries) were lacking proper expertise, infrastructure and equipment.

In the framework of e-Learning, in November 2018 the Higher Education Learning Methodologies and Technologies Online (HELMeTO) task force was created. The task force promotes a multidisciplinary platform for cross-fertilization of knowledge and for sharing research experience in the fields of methodologies and technologies for distance learning. The task force organized the First International HELMeTO Workshop (http: / / sites.google.com/view/helmeto2019/homepage accessed on 1 July 2021) that was held in Novedrate, Como, Italy in June 2019, at the headquarters of the eCampus Online University. More than 50 researchers and experts participated in the event, wherein 30 scientific contributions were presented. A collection of selected and extended contributions has been published in [8] as chapters of a Springer volume of the Communications in Computer and Information Science (CCIS) book series.

Despite the complex and rapidly evolving scenario due to the COVID-19 pandemic, the HELMeTO task force felt the need to carry on in organizing a second edition of the Workshop. The event was organized by the University of Bari (Italy) and was successfully held fully online in September 2020. The theme of HELMeTO 2020 (http:/ / www.helmeto2020bari.com accessed on 1 July 2021) was "Bridges and Mediation in Higher Distance Education". HELMeTO 2020 mainly focused on discussing novel online learning delivery solutions for all the higher education institutions rather than for online universities only. With the present paper, we share with the scientific community a report on the outcomes of HELMeTO 2020.

HELMeTO 2020 became a moment for sharing and discussing the key issues for online higher education for both the present situation and the near future. The event was characterized by two main scientific streams, namely "Methodologies for e-Learning" and "Information Technologies for e-Learning". Additionally, a cross-track on "Facing the COVID-19 Emergency in Higher Education Teaching and Learning" was also arranged.

Some of the main topics tackled by the workshop were didactic models for e-Learning, technological solutions for distance learning, educational data analysis and online evaluation methods. Most of these topics were widely discussed informally within the academic community and are recurrent conference topics, but the time has come for establishing a specific recurrent event dedicated to online higher education, especially in the European area.

The interest in the event was confirmed by the eCampus University (Italy), SIREM Scientific Society and Springer that provided their scientific support to the event. Moreover, other internationally recognized online universities, namely Universidad Internacional de La Rioja (UNIR) (Spain), UNITELMA Sapienza (Italy), the European Institute for Learning, Innovation and Cooperation (Germany), and "Giustino Fortunato" University (Italy), were involved in the event's organization.

The International Technical Program Committee (TPC) of HELMeTO 2020 was composed of valuable and international researchers and professors from both online and traditional face-to-face universities. In particular, the TPC members came from nine differ- 
ent countries, namely Italy, Finland, Spain, the Netherlands, India, France, China, the USA and Morocco. The international academic community answered the HELMeTO 2020 [9] call for papers with 59 high-quality proposals. Each proposal was reviewed by at least three members of the TPC who decided to accept 39 papers for oral presentation at the virtual workshop. Finally, a Springer post-proceedings book composed of 26 selected contributions has recently been published in [9].

Moreover, three invited speakers of a high scientific profile, namely Sir John Daniel (Acsenda School of Management, Vancouver, Canada), Prof. Pierpaolo Limone (University of Foggia, Italy) and Prof. Svetlana Karkina (Federal University of Kazan, Russia) enriched the overall program of HELMeTO 2020, together with the first edition of the HELMeTo Award, promoted within the workshop by offering two prizes: one reserved for contributions related to the pedagogical-methodological area and one for contributions from the technological area.

The rest of this report is focused on reviewing the 26 contributions included as full or short papers in the post-proceedings of HELMeTO 2020 [9]. In the first section, we summarize the contributions in the field of methodologies for e-Learning. Then, in the second section, we focus on the works dealing with technologies for e-Learning and, in the third section, we briefly discuss the papers collected and accepted for the special track about the COVID-19 emergency in higher education. Finally, the last section provides some final remarks and draws some conclusions and provides future perspectives.

\section{Methodologies for e-Learning}

Online higher education offers several topics for further study, both theoretical and empirical, in the specific context of the methodologies, assumed as the backbone of any educational intervention activity. Thus, HELMeTO 2020 accepted contributions under the umbrella of methodologies for e-Learning. We divided them into two main topics, namely "Online learning pedagogical frameworks: models, perspectives and application" and "Online learning strategies and resources: e-tutoring, communities, webinars and tools".

\subsection{Online Learning Pedagogical Frameworks: Models, Perspectives and Application}

The work of Frisch et al. allows us to know the investigations of the Information, Innovation, Didactiques, Documentation, Education, Knowledge, Ingénierie (IDEKI) network, and proposes the construction of a "collective intelligence" to reflect on hybrid modes of online professional development. Through the description of two different professional communities, and specifically the analysis of their practices and the impact on the professional development of the actors, the work makes explicit the connection between research and some dimensions of real professional activity, crossing the writings on teaching and the fields of professionalization, construction of professionalism, accompaniment and professional development. The study carried out with the multiple-case approach, described by Panciroli et al., analyzes the blended model implemented in a university course and two undergraduate laboratories at the University of Bologna. It aimed to investigate how three specific teaching strategies (art-based learning, inverted learning and role play) support blended and online teaching by means of student-to-student and student-to-teacher engagement and interactions. Toto and Limone investigated through the the Unified Theory of Acceptance and Use of Technology (UTAUT) questionnaire the degree and forms of acceptance of technologies by teachers involved in online courses. They delve into the theme of teachers' mental representations, perceptions and visions, regarding the use of digital technologies in the classroom and provided an innovative perspective on the use of digital technologies in the school context. The work of Piccino investigates the forms of reasoning that can be developed in students in an online environment, both real and virtual, through narrative and paradigmatic thinking. It explores the representations of students, as linked to cognitive styles, which orient personal dispositions towards one or the other modality of organization of teaching, and identifies the variables that students 
take as a point of reference to establish the personal meaning attributed to the experiences of learning in person and at a distance.

\subsection{Online Learning Strategies and Resources: E-tutoring, Communities, Webinars and Tools}

Raviolo et al. provide a map of the specific activities of e-tutoring at the eCampus Online University, focusing on online tutors (TOLs) and disciplinary tutors (TDs). The work shows how the hybrid role of the e-tutor does not imply a specific disciplinary competence, but rather a pedagogical background linked to the concrete design of the student's learning experience within the online university. The work of Ferrari and Triacca invites one to reflect on the "three ages" of media-technology for distance education, technologysupported groups and technology for community development-and on the increasingly strategic role of the e-tutor in new learning contexts. It describes the strategic role of the e-tutor in building the online community investigated through qualitative and quantitative methods on nine degree courses at the "Sacro Cuore" University of Milan. Stebbings et al. investigate the function of webinars in the progression of student learning as regards a distance learning course at Manchester Metropolitan University. The objectives of the study were to assess the effectiveness of webinar-based learning for achieving unity and student progression, and for gaining insight into factors that can help to improve students in the undergraduate degree in exercise and sports. The work of Ebere et al. statistically analyzes the impact of the distance learning modality of the undergraduate introductory course in biology on student learning. The study explores the differential effects of classroom instruction and distance teaching among educational science students in a basic biology course. Although there were no significant effects on students' achievement, on the other hand, effects on the dynamism of the shareholding were noted. De Giuseppe and colleagues present an inclusive training model in blended mode for the development of active citizenship skills, called "Education for Sustainable Development (ESD)". The longitudinal multi-perspective pilot study conducted between 2014 and 2017, at the University of Salerno, shows that the inverted inclusion model has favored the promotion of an inclusive context, through a modification of one's own style of pro-social attribution.

\section{Information Technology for e-Learning}

IT technologies play an important role in supporting different aspects and dimensions of distance learning in higher education. Thus, HELMeTO 2020 accepted contributions under the umbrella of learning technologies. We divided them into two main topics, namely "The challenge of implementing emerging technology solutions for online learning" and "Online learning technologies in practice".

\subsection{The Challenge of Implementing Emerging Technology Solutions for Online Learning}

As regards the first topic, Casalino et al. discuss the importance of taking into consideration, when building education data mining models, the streaming aspects related to digital footprints, which each student continuously generates while interacting with virtual learning environments. De Carolis et al. present the preliminary results achieved by a computer vision module that recognizes facial expressions associated with emotions, which typically arise during a distance learning process. Eradze et al. carry out a statistical analysis for assessing the educational values of videos and considering the feedback provided by the students after each video class. Umezawa et al. propose a method to assess the attention degree of students considering the time spent on a browser and the analysis of their electroencephalogram. The authors carried out an experiment to test the proposed method, which included two groups of students who learned the C and Scratch languages, respectively. The work of Robert et al. introduces a virtual reality application for learning in artificial intelligence education. The application has been experimented with in a real context of introducing pupils to neural networks and the gradient descent algorithm. 


\subsection{Online Learning Technologies in Practice}

Regarding the second topic, the work of Karkina et al. explores the possibilities of an online musical education, based on signature pedagogy for the improvement of creative art skills. Quantitative (students' essays and musical instrumental performance) and qualitative (students' feedback) data were collected from the online resource at Kazan Federal University. Ardimento and Scalera discuss the results of comparing flipped learning and traditional learning in an object-oriented programming course at the University of Bari. They divided their classroom into two groups that experimented with the two different learning approaches. Cisternino et al. discuss a teaching experience at the University of Pisa. Specifically, the authors exploited a cloud-based virtual lab to allow students to carry out practical activities in the framework of cloud computing and distributed databases courses. Fazzolari et al. describe a nationwide initiative for the implementation of online teacher training courses and materials on digital culture. The main aim of the initiative is to enhance distance learning and to make it more accessible at every level of education.

\section{Facing the COVID-19 Emergency in Higher Education Teaching and Learning}

The COVID-19 pandemic has heavily impacted the world of higher education. If online universities were somehow prepared for this unfortunate situation, although the challenge is still apparent for blended courses characterized by face-to-face practice-oriented activities, traditional universities paid the highest price in seeing themselves basically converging towards distance learning in a short time. On the other hand, the pandemic emergency has clearly boosted theories and practices of distance learning in higher education. HELMeTO 2020 launched a call for papers reserved for a COVID-19 special track, and the impressive amount of papers received for this special track proves both the successful effort made by traditional courses in turning online and the response of the higher educational research community in defining frameworks and models for distance learning during the pandemic. The COVID-19 special track relied on many submissions that were carefully selected and turned into two topics. The first topic pooled contributions focused on tools and practices for facing the COVID-19 emergency in higher education, while the second topic gathered studies aimed at providing frameworks and overviews.

\subsection{Facing the COVID-19 Emergency: Tools and Practices}

As regards the first topic, Bonavolontà et al. investigate the continuity of the educational relationship between teachers and young tennis players during lockdown as well as the levels of physical activity, enjoyment and motivation in the emergency context. On the basis of the encouraging results, they reflect on how the emergency may represent a fresh start for distance learning in sport activities. The work of Kővári and Bak aims at assessing digital competences and online social presence among university students of the University of Pannonia during COVID-19 lockdown. By means of a survey, the authors have found a connection between Internet skills and online social presence, a positive correlation between age and Internet skills and a similar online social presence between men and women. The work of Agrati and Vinci presents the model of didactic-organizational solutions that have been adopted for virtual internships of the Educational Sciences university program at the "Giustino Fortunato" University during COVID-19 lockdown. Their results suggest that webinars providing targeted e-tivities can be successfully used to simulate problem scenarios and develop process intervention skills. Finally, Mort and Daniel describe how the Acsenda School of Management (ASM) in Vancouver (Canada) faced the COVID-19 crisis using the approach of change leadership. The ASM was engaged in change management to integrate technology-enhanced learning throughout its curriculum. This approach eventually created a resilient institution that will be able to thrive in the uncertain times that will follow COVID-19. 


\subsection{Facing the COVID-19 Emergency: Frameworks and Overviews}

Concerning the second COVID-19-related topic, Bruschi et al. discuss the early results of a study on the advantages experienced by university teachers, already involved in a specific training program on the online open course model at the University of Turin, facing the COVID-19 emergency. Hana Ait Si Ahmad et al. present a study on the implementation of online teaching at Cadi Ayyad University, Morocco, as a starting point for a strategic plan for the digital transformation of the university after the COVID-19 emergency, highlighting six pillars that seem to be the most relevant to build the university of tomorrow. Fabbri et al describe the implementation of a blended learning model in the Department of Education, Humanities and Intercultural Communication at the University of Siena (Italy). The crisis is seen as a "critical organizational incident", which triggered a process of building a new community, more reflective and able to evaluate and rethink the degree of effectiveness of its pedagogical practices. Loredana Perla et al. present an investigation aimed at identifying the main constituents of the imposed digital "metamorphosis" and the forms and formats of the hybridization introduced in educational mediation during the COVID-19 crisis. They identify some indications of a profound rethinking of university didactic mediation in a hybrid digital direction that seem to be here to stay even after the return to the normality of face-to-face teaching.

\section{Conclusions}

The 2020 edition of the International Workshop on Higher Education Learning Methodologies and Technologies Online (HELMeTO 2020) took place in an exceptional moment that emphasized the magnitude of distance learning well beyond higher education. Most contributions focused on COVID-19 have been presented in a specific track, but the echoes of the pandemic situation come out clear even from the research presented in the conference's main sessions, focused on learning technologies and methodologies. The contributions on the pedagogical frameworks in professional training and higher education, the focus on online communities and tutoring, the impact of emerging technology solutions like artificial intelligence and learning data analysis gave us the impression of a fast-developing scenario in which the worldwide diffusion of online learning to face the epidemic emergency is having an accelerating effect in the dissemination and consolidation of theoretical models and operative implementations. The new scenario will probably see online learning and blended learning become usual options in higher education. From the 2020 HELMeTO edition we can highlight a specific focus on the learning experience of the student, from a methodological perspective with the studies on tutoring and active learning approaches, and, from the technological side, focusing on personalizing solutions supported by data analysis, virtual reality and in-depth analysis of the human-computer interface in online learning environments.

Author Contributions: The authors contributed equally to this work. All authors have read and agreed to the published version of the manuscript.

Funding: The contribution of Pietro Ducange to this work is supported by the Italian Ministry of Education and Research (MIUR), in the framework of the CrossLab project (Departments of Excellence).

Institutional Review Board Statement: Not applicable.

Informed Consent Statement: Not applicable.

Data Availability Statement: Not applicable.

Conflicts of Interest: The authors declare no conflict of interest. 


\section{References}

1. Gaskell, A.; Mills, R. The quality and reputation of open, distance and e-learning: What are the challenges? Open Learn. J. Open Distance E-Learn. 2014, 29, 190-205. [CrossRef]

2. Stracke, C.M.; Downes, S.; Conole, G.; Burgos, D.; Nascimbeni, F. Are MOOCs open educational resources?: A literature review on history, definitions and typologies of OER and MOOCs. Open Prax. 2019, 11, 331-341. [CrossRef]

3. Stracke, C.M. Quality Frameworks and Learning Design for Open Education. Int. Rev. Res. Open Distrib. Learn. 2019, 20, 180-203. [CrossRef]

4. Bonk, C.; Lee, M.; Reeves, T.; Reynolds, T.H. MOOCs and Open Education Around the World; Routledge: New York, NY, USA 2015.

5. Stracke, C.M. The Need to Change Education towards Open Learning. In The Need for Change in Education: Openness as Default? Proceedings of 4th International Conference Learning Innovations and Learning Quality (LINQ); Stracke, C.M., Shamarina-Heidenreich, T., Eds.; Logos: Oakland, CA, USA, 2015; pp. 11-23. [CrossRef]

6. Stracke, C.M. Open education and learning quality: The need for changing strategies and learning experiences. In Proceedings of the 2017 IEEE Global Engineering Education Conference (EDUCON), Athens, Greece, 25-28 April 2017; pp. 1049-1053. [CrossRef]

7. Gaskell, A. Online Distance Education: Towards a Research Agenda. Open Learn. 2016, 31, 76-79. [CrossRef]

8. Burgos, D.; Cimitile, M.; Ducange, P.; Pecori, R.; Picerno, P.; Raviolo, P.; Stracke, C.M. Learning Methodologies and Technologies Online. International Workshop on Higher Education Learning Methodologies and Technologies Online 2019; Springer CCIS Book Series; Springer: Cham, Switzerland, 2020; Volume 1091. [CrossRef]

9. Agrati, L.S.; Burgos, D.; Ducange, P.; Limone, P.; Perla, L.; Picerno, P.; Raviolo, P.; Stracke, C.M. Bridges and Mediation in Higher Distance Education: International Workshop on Higher Education Learning Methodologies and Technologies Online 2020; Springer CCIS Book Series; Springer: Cham, Switzerlands, 2021; Volume 1344. [CrossRef] 